the forces that give rise to the inverted movement. Since the apex rises from an inch to one and 2 half inches above the border of the first rib we conclude that the site of deposit will be situated from an inch to one and a half inches below the summit of the lung. This mechanical explanation of the valnerability of the apices of the lungs to tuberculosis in the human subject is the more interesting by reason of the fact that the proclivity to tuberculous disease of the basal lobe of the lung in cattle is in all probability likewise dne to mechanical causes.

The practical bearing of the theory which we have advanced is the enormons importance of developing the muscles of the shoulder girdle with the object of "pulling the chest into shape," as Woods Hutchinson so ably and graphically puts it. To this end tree climbing, ball throwing, horizontal ladder and bar exercises-indeed, any muscular manceuvre which brings into play the great pectoral muscles should te sedulously and systematically carried out. Before leaving the subject we should like to suggest that the theory which we have put forward is pertinent to explain other abnormal conditions that occur at the apex of the lung, and in this respect we would call attention to the development of emphysema in this situation.

Beference.-Woods Hutchinson : Human and Comparative Pathology.

\section{THE SURGICAL TREATMEN'T OF ULCERS OF THE STOMACH}

\section{WHICH ARF OR HAVE BEHN COMPLICATED WITH SEVERE HASMORBHAGE.}

BY C. B. K E T T L Y, F.R.O.S. ENG., SURGBOY TO THE WEST LONDON HOSPITAL.

IT is of practical importance to distinguish between severe gastric hæmorrbages and slight ones. In my experience there has so far been not much difficulty in placing individual cases in one or other of these two classes. Severe bæmorrhages are such as show, either by the vomit or by the stool, that pints, if not quarts, of fluid, chiefly blood, have escaped into either the stomach or the dnodenum. It seems a comparatively secondary matter whether a given case is gastric, or affects the upper three and a half inches of the duodenum, which are quite accessible during any operation that may be performed to expose the stomach. If we are satisfied that a case is one of severe hæmorrhage from a peptic ulcer, we have made the first essential step. Precise localisation, though desirable, must generally be left to be determined by the operation, if one is performed. If anyone thinks the above preliminary remarks so obvious as to be superfluous let him read the most interesting debate on Mr. Mayo Robson's recent paper at Edinburgh ${ }^{1}$ or Dr. Byrom Bramwell's clinical lecture, ${ }^{2}$ and he will find in these scarcely any regard paid to the distinotion between severe and slight hæmorrhages.

Both severe and slight bæmorrhages have their dangers, remote in the slight cases, immediate and remote in the severe ones. Cases of slight hæmatemesis are not, however, as a rule, treated mainly for the hrmatemesis, but on account of the disease of which the blood-stained vomit is a sign. I propose now to deal with three cases of the severe class which have come under my care in the past two years, and also to refer to the case of a personal friend of mine who was not, however, attended by me but who died abroad. These four form the total of my experience since April, 1899, when $m y$ interest was first a wakened in the subject by $m$ y friend, Dr. Leonard Dobson, who had already come to the conclusion that the recent, though past, occurrence of severe bæmorrhage from the stomach indicated a condition requiring surgical treatment.

CASE 1. Gastric ulcer adherent to the diaphragm and the panoreas whioh formed its base. Considerable hamorrhages, the last neariy tatal; the adhesions separated and the ulcer scraped and sutured; recovery; recurrence of pain; gastro. enterostomy; cure. - The patient, a female, aged 20 years, was anæmic but very well nourished. She had had three attacks of rather severe hæmatemesis, two wbile in the West London Hospital in October, 1898. In one of the latter

1 The Scottish Medical and Surgical Journal, March, 1901. 2 The Lancet, March 9th, 1901, p. 687. she vomited a pint and a half of blood. After medical treatment under Dr. F. G. D. Drewitt she went out apparently quite cured, but in spite of careful diet the gastric symptoms returned in a month. She then had another very severe hæmorrhage, and Dr. Dobson, whose patient she was, brought her to the hospital with a view to operation. Her pain was in the epigastrium and between the shoulders. There was a tender spot two inches below the xiphoid as well as marked tenderness in the left hypochondrium. The special features of the operation (April 14th, 1899) were: (1) the position of the ulcer (2) how it was found; and (3) how it was dealt with. 1. It was near the lesser curvature and osophageal opening on the posterior surface and was firmly adherent to the diaphragm and the upper edge of the pancreas, which formed its base, as it had completely perforated. It was circular and seven-eighths of an inch in diameter. 2. The search for it was long and difficult. External palpation of the vimcus discovered nothing. An opening was made in the anterior wall and with the finger inside the first part of the duodenum and all the stomach, except the part nearest the œsophageal opening, were reached and were systematically searched. Then a speculum was uzed. Lastly, the part where the ulcer proved to be was brought within reach of the tip of the left index finger, by long and very gentle dragging on the posterior wall with the right finger and thumb. 3. The treatment of the ulcer now involved division of the left rectus and prolongation of the median ineigion upwards to give room, as well as a sufficient perpendicular opening through the omentum into the lesser cavity of the peritoneum. Gauze packing was employed. Oareful separation was made of the base of the ulcer from the pancreas and diaphragm; there was an area of thickening here two or three inches in diameter. The ulcer edges were now scraped, which procedure about doubled its diameter. Three silkworm gut sutures were passed, half an inch apart, through all the coats of the stomach, in such a way that the loops were outside and the ends inside the organ. The original opening in the anterior wall was now utilised in order to tie these three sutures with the knots inside the stomach. Although half an inch apart they had such a grip on the stomach wall that they seemed to close the hole completely. However, they were now backed up by a row of Lembert's sutures of fine silkworm gut. The anterior gastric opening was then closed by Lembert's sutures. Gauze drains were left in for four days. Uninterrupted recovery followed. Nothing but hot water and a little Apollinaris or lemonade were allowed for more than a week. Solid food was not allowed for a month. The highest temperature was $99.5^{\circ} \mathrm{F}$. and the lowest $976^{\circ}$.

The patient remained well for some months, returning to work in the country. She then began to be troubled with pain and tenderness in the epigastric region again. On Oct. $19 t h, 1900$, a second laparotomy was performed. No adhesions were found, but the lesser cavity of the omentum was not open ad. An anterior gastro-enterostomy was done with a Murphy's button. The result so far (June, 1901) is apparently perfect except that no sign of the button has been found either by $x$ rays or otherwise. The patient is following her usual daily work and she has written: "I have never felt better in my life."

It is possible that ulceration recurred in this case or that adhesions of the site of the old ulcer to the scraped surface of the diaphragm (or the pancreas) occurred and made the movements of the stomach painful. It is possible that if $I$ had fully dilated the pylorus at the time of the first operation-i.e., to an inside circumference of four and a half inches-I might, as in Case 3 (about to be related), have been spared the necessity of a second operation. For the notes of the case I am indebted to Mr. G. F. Briggs and Mr. O. Inchley.

CASE 2. Severe gastric homorrhage; rest and opium and rectal feeding; no operation; death on the twelfth day.-The patient was a female, aged 32 years. I was asked to see her on the morning of Sept. $25 \mathrm{th}, 1899$, because, after fainting no less than five times in the preceding 24 hours and passing black stools, she had vomited three or four pints of dark blood or bloody fluid on the evening before. I saw the fluid in a bowl. She had suffered from pain after taking food for a week. I sent her into the West London Hospital, intending to see her again at my usual visit the next day, but as I sent her under a physician into a medical ward, and " ont of sight is ont of mind," I forgot all about the case until after the poor girl was dead. According to the 
note of Mr. T. Wood Hill, the house physician, on Sept. 25th her motions were black. As a rule the patient was constipated, she suffered from headaches, often from faints, and was pale in colour. Her abdomen was "resonant, very rigid, extremely tender." Rectal feeding was employed and the patient was given ice to suck. One-sixth of a grain of opium was given every six hours. On the 26 th the note was: "Slept well; melæna this morning; motions fluid, blackish red." On the 27th she had slept well and there was no pain in the stomach. On the 28 th the pain in the stomach was very severe and the stools were large and dark. On the 29th she was "quite comfortable." On the 30 th three out of seven enemata returned. There were pain in the abdomen and great weakness. The palse was poor before the enemata. Two-minim doses of solution of strychnine, "si opus sit," were ordered. On Oct. 2nd enemata and meat suppositories were given every four bours alternately. The pain was less. The pulse was of poor volume. On the 5 th the gastric pain ceased. On the morning of the 7th the patient was saddenly seized with pain. The pulse was rapid and very poor in volume. There was no sickness. At 8 P.M. the pulse at the wrist was imperceptible. Venous transfusion was performed, four pints of saline solution being injected into the median basilic. The temperature afterwards went up suddenly to $106.8^{\circ} \mathrm{F}$. and the patient died at $4.25 \mathrm{~A} . \mathrm{M}$. No post-mortem examination was allowed. Brandy had been given both by the mouth and with the enemata (two ounces per 24 hours) from Sept. $28 \mathrm{th}$, and bismuth mixture from Oct. $4 \mathrm{th}$. The temperature chart is interesting. The range was between normal and one degree subnormal until the final rise.

I am sorry to say that I did not remember to inquire about this case until some months had elapsed, when I was grieved to hear the course which things had taken. One question which arises in this case is, Had perforation and localised peritonitis taken place? I do not think so. Dr. E. A. Saunders and I now think that the patient's life might possibly have been saved by operation, and that the second day after her admission into hospital would have been the time to choose in this case. At all events, I did no good by " trying medical treatment first" and "waiting for a recurrence of the hæmorrhage."

CASE 3 Long history of chronio gastrio trouble; severe hamorrhages; Loreta's operation (pylorus stretched to four and a halt inches internal circumferenot); recovery; quite well up to one year aftervards. - The patient was a wornan, aged 39 years, who had been married for 14 years and had been a widow for nine years. She had had two children. There was a tuberculous family history (husband and son). She had suffered from indigestion since childhood and from flatulence. Since her husband's death she bad worked hard and had suffered more from indigestion. She had had a cough for years. Pain began from one-quarter to half an hour after taking food. Lately the pain had been more delayed and was of a less defined cbaracter-a "sinking, uneasy sensation." In the preceding March she had a severe attack, vomiting "some quarts of blood." In October she brought up more blood. This patient, like the first, was also placed under $m y$ care for operation by Dr. Leonard Dobson. She took liquid and light food well after admission and improved in appearance. The operation was carried out on April 20th. The patient had been prepared for several days by purgatives and enemata. A median epigastric incision was made. The pylorus was found to be very hard and thickened. It would not admit the tip of the little finger and it felt quite rigid. No ulcer was seen or felt; but it was not thought fair to the patient to add to her risk by making a prolonged and rigid search for ulcer. A Loreta's operation was decided upon, as I had previonsly seen an excellent and lasting result follow this operation when performed on a similar pylorus. Through a small opening in the anterior stomach wall a three-bladed anal dilator was passed through the pylorus until the blades were wholly inside the stomach and duodenum ; 37 turns of the screw, made very gradually, dilated the pylorus to an inside circumference of four and a half inches. The wound in the stomach wall was closed by three sutures penetrating all the coats and tied with their knots inside the lumen, and by a superimposed row of 12 Lembert's sutures. Two small drains were carried obliquely from the parietal wound to near the stomach wound and they were removed in a few days. Some ether sickness occurred during the night. On the $22 n d$ the patient vomited once and on the 23rd once. On the 26 th she was very hungry. There are no other notes. Convalescence was rapid and uninterrupted. She was fed for a week on beeftea by the mouth (half an ounce every two hours, after vomiting had ceased), and peptoniked milk enemata containing plasmon. A week after the operation she also took by the mouth one drachm of milk every two hours, with plasmon, on drachm to four ounces of milk, and afterwards milk-and soda and Benger's food, and on May 1st mutton, fish, 8c. She went out well on May 26th and has remained well. At Christmas she wrote, "I can now take quite ordinary food and have no signs of indigestion." The notes of the case were kindly supplied by Dr. Maurice Dee.

OASE 4. Duodenal ulcer; perforation of pancreaticoduodenal artery; hamatemesis and melcena; no operation; death.-A military officer, aged 40 years, was taken into hospital with a history of severe recent bæmatemesis and melæna. He had just arrived at this place (in India) after a long journey. He had fainted while walking across the room with a glass in his hand. He bad only just returned from leave in England, where he had been under treatment for a pain which came on regularly about an hour after retiring to bed-i e., about the time a late dinner would be passing in to the duodenum. Gastric trouble was recognised, but a precise diagnosis was not made, and in Fngland the patient was relieved by treatment. In India the liver was suspected. He was placed on a milk diet when taken into hospital, but he died the next day. Post mortem an ulcer of the duodenum was found, perforating the pancreaticoduodenal artery. There were circumstances of special difficulty attending the diagnosis and treatment of this case which progressed chiefly during the long journey from England to India. This life was one of the highest value not only to the patient's relatives but to his country. For the details of the case I am indebted to my friend and old house surgeon, Mr. H. G. Wharry. In India the patient was under the care of another old house surgeon of mine, an exceedingly able and painstaking man. The patient's family are intimate friends of mine, and an old patient of mine lay in the next bed in the Indian hospital. This case was thus brought under my notice in four distinct ways.

Assuming that it is right for surgery to act in cases of severe gastric bæmorrbage the first questions which arise are when and how. It is natural to turn for guidance to the experience of Billroth and his assistants, the latter still living and working with enthusiasm and with brilliance com. parable to those of their great master. This school founded modern gastric surgery and bas had a large share in its further development. Von Miculicz of Breslau gives a gloomy account of the result of operating during the progress of acute hæmorrhage. Only two patients had recovered out of a considerable number-one of Roux's and one of his own. He himself had lost three. Mr. Mayo Robson has had a successful case - that of a woman who was operated upon on July $6 \mathrm{th}, 1900$. Seven bleeding points were found. Two were ligatured en masse and the other five stopped "on exposure. to air." Posterior gastro-enterostomy with bone bobbin was performed. There is another successful case just reported by Dr. Brunton Angus. ${ }^{3}$ The patient was attacked by venous thrombosis in both legs about a fortnight after the operation. The ulcer was ligatured en masse. Many other cases will soon be reported as a result of the attention which is now being directed to the subject, and possibly not a few failures. will be passed over in modest silence.

Now death from gastric hæmorrhage is nearly always death from recurrent hæmorrhage. Further, there is no need to operate quickly in order to avert peritonitis as in cases of perforation; and the patient is usually alarmed and depressed to fainting during the bleeding. Lastly, a day or two usually intervene between successive hæmorrhages. These considerations would lead one to defer operation until actually present bæmorrhage bad ceased and shock had passed away. But one must not expect reaction after large hamorrhages to restore to the pulse its original strength and volume. When the patient has fairly rallied and his or her extremities have become warm, with or without external heating appliances, if operation is decided on the sooner it. is done the less will be the risk of being overtaken by another (and possibly fatal) bleeding.

The next consideration is the mide of operating. It must be remembered that while the gastric ulcers which perforate and cause peritonitis are nearly all on the anterior wall, those which perforate and bleed are, in a large proportion, 
on the posterior wall and especially such as adhere by their bases to the pancreas or to its near neighbourhood. Therefore, when these latter have been exposed by operation it has generally been found diflicult simply to take up the bleeding point and to tie it securely. Resort has been had either to ligature of the ulcer en masse or to the actual cantery, and the result has been disastrous. ${ }^{4}$ I am inclined to think that I was fully justified in my case in preferring to separate the adhesions of the stomach to the pancreas and diaphragm, scrape the ulcer and close the resulting gastric wound by suture. This was, as I have said, a long process, but if a patient is in fairly good condition, is kept warm, is not allowed to bleed, and is not over-dosed with anæsthetic, and if also the vigilance of the antiseptic precantions is not allowed to relax, I do not believe that a moderate prolongation of an operation seriously endangers its success. Bat $I$ hold it to be of the first consequence, especially with feeble subjects, to produce only so much anæathesia as is necessary to protect the patient from serious pain. The dose should not be increased as a luxury for the surgeon. I do not recommend separation of a bleeding ulcer from the pancreas or the diaphraym as a routine procedure, because I think shorter and easier measures will generally suffice.

In these days the old general rule of surgery to cut down upon a bleeding vessel and to tie it is modified by many exceptions, especially in parts where compression can be applied. Unfortunately, compression is seldom if ever applicable to gastric hæmorrhages. Even temporary pressure by forceps should not be relied upon to permanently check bleeding from the vessels of the stomach. Experience of gastric operations proves that, where practicable, a ligature should be put on before removing the forceps. Not only has it often proved difficult to find the bleeding point or points in operations for gastric hæmorrhage, but also, when found, the source of bleeding has sometimes proved so friable or in such a situation that effective ligature, even en masse, has not been possible. And, as I have already said, the cautery has not given good results. There remain, however, at least three other powerful agents which may be used in nearly every part of the body as protective against recurrent hæmorrhage, viz. : (1) rest (local and general), (2) aseptic measures, and (3) gauze (especially iodoform gauze) packing. The first two can be used more or less successfully by the physician, but they can be effected more thoroughly and more lastingly by the surgeon, and the third, of coarse, can only be employed by the surgeon.

It is well known that the arrest of bleeding from an eroded ressel in the stomach is brought atout by the formation of a clot in it. It is often assumed when the bleeding recommences that some excitement of the circulation has displaced the clot. From what takes place in regions of the body more open to observation I should infer that usually not mechanical displacement but septic disintegration has been the chief agent in starting the bleeding afresb. What a difference there is in the value of plugging in the present as compared with the past! That difference is mainly due to the fact that formerly a septic wound used to be plugged with septic material, while now an aseptic wound is plugged with aseptic or with antiseptic material. No doubt the secretions of the stomach, especially of the normal stomach, have a bactericidal power, but examinations of matters vomited show that power to be limited. In a case of recent severe hæmatemesis there is a stomach containing blood and perhaps food at the temperature of the body and in contact with a diseased area, the ulcer, and with a mucous membrane not secreting normally.

The stomach can be washed out through the gullet, and some medical men recommend hot-water lavage for cases of hamatemesis. It is rather a disturbing process of which I have had no experience in cases of hæmorrhage, but I should hesitate to condemn it on mere a priori grounds.

"Von Miculicz writes that, besides his sucressful case, "I have opened the stomach three times for acute hromorrhage. The ulcer lay in the neighbourbood of the pylorus in the posterior wall and adhered in two of the cases to the substance of the pancreas. The base and surround ings of the ulcer were so much infiltrated that securing the vessel with a ligature or with a suture was out of the question. I was satisfied with applying the thermo cautery to the base of the ulcer. The patients died in the course of the next 24 or 48 hours of collapse. Billroth and other operators had no better results in similar cases." Körte of Berlin in the discussion after von Miculicz's paperdescribed a similar case of his own. After the cauterisation the bleeding continued till death occurred eight days afterwards. The artery eroded was found, post mortem, to be the splenic. In a publication last year, 1900, von Miculicz does not modify his opinion or add to the above facts.
An objection to it is that if the asepticity of the stomach is to be preserved the lavage must be frequently repeated, and in many patients it can only become a gentle process when the patient has been long accustomed to it. There is also a slight risk of perforating a diseased stomach. And what if the diagnosis were wrong and the stomach already perforated

If a stomach is opened and cleansed by the surgeon, how is the cleansing or asepticising to be made permanent or at least enduring? A very extensive experience by various surgeons agrees that if, by a successful gastro-enterostomy or pyloroplasty, or even mere dilatation of the pylorus, we remove all spasmodic or other obstruction to the free flow of stomach contents into the small intestine, a great and a rapid improvement takes place in the bealth of the stomach. Indigestion ceases and ulcers heal. In ordinary cases, therefore, one of these operations alone would suffice. Mr. Caird recommends the performance of a gastrostomy as a mode of giving rest to the stomach and regards such a procedure as analogous to one for drainage of a diseased urinary bladder. Mr. M'Gillivray points out an essential difference: urine is always flowing into the latter, but we are not obliged to be always putring focd into the stomach. Moreover, Mr. Caird suggests that the gastrostomy should be done by Witzel's method. The calibre of the small i ubber drain or catheter generally used in Wilzel's gastrostomy compares unfavourably for drainage with the one-and-a-half inch or two-inch diameter of a gastro-enterostomy wound.

A question with a practical bearing is how do gastroenterostomy, pyloroplatty, and Loreta's operation come to act so beneficially on peptic ulcers? The explaration generally adopted is that they prevent stasis of the stomach contents due to constriction of the pylorus. But duodenal ulcers lie beyond the pylorus altogether, and peptic ulcers are found up to, but not beyond, where bile and pancreatic juice enter the duodenum. It is reasonable to infer that the presence of these juices is a protection against gastric ulcer. We were, most of us, I tbink, until recently under the impression that much bile in the stomach would cause discomfort and probably vomiting. A remarkable case is reported by Mr. B. G. A. Moy nihan. ${ }^{5}$ After an accident which completely separated the duodenum from the jejunum, that surgeon closed the distal end of the duodenum and did a gastro-jejunostomy. All the secretions of both the liver and pancreas now necessarily only reached the intestine by flowing backwards through the stomach. The patient lived for two months in "perfect health" Death then resulted from perforation caused by the Murphy's button.

I suggest that the curative effect of gastro-enterostomy, \&c., is due in some measure to the passage of bile and pancreatic juice into the stomach. My colleague, $\mathrm{Mr}$. L. A. Bidweil, tells me, as supporting this suggestion, that traces of bile can be found in the stomach contents after gastro-enterostomy.

To return for a moment to Mr. Caird's suggestion alrt ady referred to. no mere gastrostomy would bring bile into the stomach. Still, it must be admitted that a sufficiently large gastrostomy opening would permit frequent and complete lavage of the stomach through it, and the patient could assist this by swallowing copious draughts of hot water-an act which would be very grateful to him and tend to remove one of the sources of distress which patients fed wholly by the rectum bave to endure. I, therefore, think that a simple direct gastrostomy wound, large enough to admit the finger, might have been good practice in such a case as that of the paient in Case 2 suprâ; and that if performed on the day after her admission into hospital it would have saved ber life, especially if the pylorus bad been well dilated at the same time. Daring the operation a quick search for the bleeding point might have been successful, but a prolonged search would not have been justified considering her state. The proper aræstbetic would have been gas with oxygen. I have tried it for gastrostomy and can strongly recommend it. Mr. R. W. Lloyd was the administrator. It has the great advantage of not being followed by vomiting.

If there is anything in the bypothesis that the cure of peptic ulcers by certain operations is due partly to regurgitation of the secretions of the liver and pancreas it would be reasonable to treat gastric ulcers by administering orally preparations of those secretions or perbaps of the fresh 
glands themselves; and all the more so, because even the hypertrophy and contraction of the pyloras often present with gastric ulcer-e.g., in Case 3-are probably of reflex and irritative origin. The ulcer, the hyperacidity, the pyloric contraction opposing the stomach movements, and at least one other as yet unknown cause, probably bacterial, act and react to exaggerate each other. Attack one or two of these successfully and the rest are weakened. Get the ulcers into a healing state and it is likely that the pyloric contraction, unless cicatricial, will abate. This is one of several reasons why $I$ respectfully differ from those who altogether discard Loreta's operation. But "that is another story."

It is possible that some readers, bearing in mind that $I \mathrm{am}$ only a surgeon, may think that I have formed an exaggerated idea of the seriousness of gastric hæmorrhage from only hearing of very severe cases. In truth, I am brought into contact with many cases of lateral curvature of the spine which have a history of present or past symptoms of gastric ulcer and slight hæmatemesis.

There remains for consideration not so much the value as the applicability of iodoform gauze packing. The objection usually urged to it is that a gastrostomy opening would have to be left for its removal. Bat such an opening as I have endeavoured to show, in partial agreement with $\mathrm{Mr}$. Oaird, might not be an unmixed evil. Or a small piece of ganze could be left in the stomach to pass per anum when free. It could be fixed against the bleeding surface by sutures attached to neighbouring points of the stomach wall (mucosa and submucosa). Every case must, of course, be considered on its own merits, and in the present state of our knowledge decision must often be difficnlt, both to the physician who does justice to surgery and to the surgeon who acknowledges, as he must, that gastric hæmorrhage treated medically does not, as a rule, prove fatal, even if severe, and that such operations as gastro-enterostomy and the excision of gastric ulcer are themselves not free from danger. But the dangers of gastro-enterostomy diminish with increasing experience of the individual operator and with the general advance of gastric surgery. Murphy's button is most likely the best means of performing gastro-enterostomy, especially for the use of the operator who is deficient in general experience. The one objection to it is its tendency to fall back into the stomach or to stick in the opening instead of passing on through the intestine; both these accidents have occurred to me but they were easily dealt with. It is a quick mode of operating, but it should not be applied in a hurry. I suspect that many failures attributed to it have been really due to want of care and deliberation in placing, adjusting, and fixing it and the margin of the two wounds it has to keep in contact, and in some cases, to faulty construction of the button.

A collection of 75 operations done in various ways by Billroth, von Hacker, Czerny, and von Miculicz, made by the last-named, showed the following decreasing percentages of mortality. The operations were for non-malignant stricture of the pylorus and for gastric ulcer " without severe complication." To the end of $1886,62 \cdot 5$ per cent.; 1887 to $1890,42 \cdot 1$ per cent.; 1891 to $1894,22 \cdot 2$ per cent.; 1895 to the beginning of 1897,10 per cent. Von Miculicz gives the following decreasing mortality percentages for the individual operations, the periods compared being before the end of 1890 with 1891-97. Resection, 393 per cent., reduced to $27 \cdot 8$ per cent. ; gastro enterostomy, 43.5 per cent., reduced to 162 per cent.; pyloroplasty, 23.8 per cent., reduced to 13.2 per cent. These figures are calculated from a total of 234 cases, collected from various sources. There can be no doubt but that increased personal experience in the selection of cases, in the choice of operation and in the mode of operating and increased practice in gastric surgery are capable of farther reducing the death-rate, and, indeed, they seem to have already done so.

With regard to the degree of danger of gastric ulcer in general when treated medically, I think that those physicians who speik of having treated so many hundreds of cases with, say, 95 or 98 per cent. or even 100 per cent. of recoveries are not giving their experience quite correctly. I suspect that inquiry would show that many of these cases had not been under the otse vation of these physicians for more than a few months, whereas gastric ulcer goes on, or keeps recurring only too frequently, for years. $\mathrm{My}$ patient in Oase 3 had had gastric symptoms for 25 years, which represent about 150 of what some people seem to call "cases."
I think the statistics advanced to prove Loreta's operation to be no safer than gastro-enterostomy must be fallacious. Loreta's operation went out of fashion at a time when all these gastric operations were more dangerous than they are now. It is certainly free from one of the serious complications of gastro-enterostomy-viz, the danger of the so-called "vicious circle," the passage of the stomach contents, not into the efferent loop of intestine, but into the afferent and so backwards through the duodenum into the stomach. The ase of Murphy's button seems to protect against this complication of gastro-enterostomy. Why should mere dilatation of the non-cicatrised pylorus be dangerous? True, it involves a gastrotomy unless done by invaginating the stomach wall on the finger. But a mere gastrotomy is a very safe procedure, as is proved by surgical experience in the removal of foreign bodies. But in favour of gastro-enterostomy remains this possibility, that it may be more likely to give a permanent cure of the ulcer itseif and of the chronic gastric catarrh. Of course, a pyloroplasty can effect every object attainable by Loreta's operation, but it must be a more serious procedure except in the case of a cicatrised pylorus so rigid that it would be dangerous to stretch, and then a pyloroplasty might not be applicable.

One of the strongest arguments in favour of surgical treatment of gastric cases which have bled severely is that it generally gives permanent health to the stomach.

Literature.-Von Miculicz: Die Chirurgische Behandlung des Chronischen Magengeschwirs, Twenty-sixth Congress of German Surgical Society, reported in Centralblatt für Chirurgie, 1897, p. 69. Doyen: Traitement Chirurgical des Affections de l'Estomac et du Duodénum, Congress of French Surgeons, Revue de Chirurgie, 1896, No. 11, p. 568. Talma: Indicationen zür Magenoperationen, Berliner Klinische Wochenschrift, 1895, No. 15. Roux : Congress of French Surgeons, 1893. Brenner: Wiener Klinische Wochenschrift, 1896, No. 48 (all the above four references are from von Miculicz). Körte: Twenty-sixth Congress of German Surgical Society, Centralblatt für Chirurgie, 1897, p. 97. Moynihan : Brit. Med. Jour., 1900, vol. ii., p. 1403. Mayo Robson: Gastric Hæmorrhage and its Surgical Treatment, Edinburgh Medico-Chirurgical Society, Feb. 6th, 1901, ThE LANCET, Feb. 9th, 1901 , p. 375. Caird : Scottish Medical and Surgical Journal, March, 1891 . M'Gillivray: Ibid. Byrom Bramwell : THE Lancer, March 9th, 1891, p 687. Brunton Angus: Brit. Med. Jour., March 23rd, 1891. Grosvenor-street, W.

\section{VITALITY AFTER SEVERE INJURY.}

\section{BY W. H. CLAYTON GREENE, B.A. CANTAB.,} M.R.O.S. ENG., L.R.C.P. LOND.

WiTH reference to the power of living after severe injury, in illustration of which a case of rupture of the inferior vena cava with survival for two and a half hours was recorded by Dr. Adrian Caddy in THe LANCET of May 25th, p. 1464, I think the following case of perforation of the stomach, diaphragm, pericardium, and heart with other injuries in which death occurred after nine hours may be of interest.

A man, aged 49 years, was admitted to St. Mary's Hospital on A pril 2nd, at 12 noon, under the care of Mr. H. W. Page, who has kindly given me permission to publish these notes. The patient, while working on a ladder in Wimpole-street, fell on to the area railings and impaled his left side. When seen in the casualty department he was conscious but was suffering from severe shock. His pulse could not be felt, but the heart could be beard beating faintly, rapidly, and irregularly. He bad evidently lost a great quantity of blood, his clothes being completely soaked by it. His forehead was bathed in perspiration and his extremities were very cold. On examining the injured part a large gaping wound was found in the left hypochondriac region from which omentum protruded and the blood flowed; several ribs appeared to be fractured, but no detailed examination was made at first owing to the condition of the patient. Four minims of strychnine were injected at once and the patient was taken to the wards where hot bottles were placed round the body and limbs. A pint of saline solution and two ounces of brandy were given bp the rectum and, the left median basilic vein having been dissected out, two pints of saline solution were injected into the circulation. The patient's condition improved so muchthe pulse being now easily felt, about 118-that at 1.25 P.M. the wound was more thoroughly explored, but nothing definite as to the source of the bleeding could be made out and it was therefore plugged with cyanide gauze. Four minims of strychnine were injected again at 1.30 P.M. $\mathrm{Mr}$. Page, on arrival at 3.15 P.M., saw the patient and decided to 